\title{
Damage Evolution of Concrete Piles Mixed with Admixtures in Marine Corrosion and Freeze-Thaw Environment
}

\author{
Yan Li $\mathbb{D}$, Bing Li $\mathbb{D}$, Lianying Zhang $\mathbb{D}$, and Chao Ma $(\mathbb{D}$ \\ Xuzhou University of Technology, Xuzhou 221008, China \\ Correspondence should be addressed to Chao Ma; mbqq2008@126.com
}

Received 22 June 2021; Revised 3 August 2021; Accepted 17 August 2021; Published 18 September 2021

Academic Editor: Shen Weijun

Copyright ( 2021 Yan Li et al. This is an open access article distributed under the Creative Commons Attribution License, which permits unrestricted use, distribution, and reproduction in any medium, provided the original work is properly cited.

\begin{abstract}
Marine corrosion and freeze-thaw environment will bring serious damage to marine concrete structures, leading to affect the safety and service life of structures. With the help of artificial climate and environment simulation laboratory, the variation of the compression strength and elastic modulus of concrete with the number of freeze-thaw cycles and corrosion time under the corrosion and freeze-thaw environment is studied. The results show that both of them firstly increase and then decrease with corrosion time. When the corrosion time is $270 \mathrm{~d}$ and the freeze-thaw time is 90 times, the strength of concrete decreases by $13 \%$ and the elastic modulus decreases by $5 \%$. Then, based on the theory of damage mechanics, the damage evolution and constitutive model of concrete under the marine corrosion and freeze-thaw environment are established. Compared with the experimental results, it is found that the model can well describe the damage evolution characteristics of concrete under marine corrosion and freeze-thaw environment. Finally, a numerical model is established on the basis of elastic modulus and strength degradation model of concrete under marine corrosion and freeze-thaw environment. Elevated pile caps of concrete pile component are taken as an example to analyze the process of damage, and the change rules of displacement, deformation, and damage of concrete pile are obtained.
\end{abstract}

\section{Introduction}

Under marine corrosion and freeze-thaw environment, damage and accumulation caused by various environmental factors to concrete materials could result in the damage of concrete structure [1-3]. The damage caused by corrosive environment to concrete is mainly due to the chemical reaction between corrosive media and substances in concrete, generating substances that are easy to lose and have no gel effect, such as $\mathrm{CaCl}, \mathrm{NaOH}$, or may generate large crystal salts, such as trisulfide hydrated calcium sulfoaluminate, to form expansion stress and cause local fracture of concrete $[4,5]$. It cannot be underestimated the damage caused by sulfate and chloride. Sulfate damages the performance of concrete itself, and chloride mainly induces and accelerates the corrosion of steel bars in concrete structures.

Many scholars have studied the damage mechanism of concrete corrosion. Cao [6] studied the mechanical properties of corroded concrete and changing rules of bearing capacity of reinforced concrete through sulfate accelerated corrosion test and proposed a concrete strength model considering sulfate corrosion and a stress-strain model of corroded concrete. Chen and Bao [7] used indentation method to study the indentation stress-strain relationship and contact damage evolution law of concrete in air, water, and hydrochloric acid solutions. The results indicate that the elastic modulus and compressive strength of concrete increase with the increase in age in water and air, while both elastic modules and compressive strength decrease in acid solution. In addition, Sahmaran et al. and Deja $[8,9]$ found that under the action of sulfate erosion, the concrete with mineral admixtures suffered internal damage and strength deterioration. Almeida [10] pointed out that sulfate had an impact on the mesopore structure of concrete, causing damage to concrete. The study on damage caused by chloride focuses on effect of chlorine salt on damage evolution of reinforcement [11] and damage characteristics of concrete [12].

The damage caused by freeze-thaw cycle of concrete mainly includes frost cracking and surface denudation. Frost 
TABLE 1: The content of different admixture concrete samples.

\begin{tabular}{lccccccc}
\hline Materials & Cement & Fly ash & Mineral powder & Sand & Coarse aggregate & Water binder ratio & Water \\
Dosage & 226 & 68 & 158 & 740 & 1112 & 0.32 & 145 \\
\hline
\end{tabular}

cracking caused by water freezing in concrete pores seriously decreases the mechanical properties of concrete, including elastic modulus, compressive strength, and tensile strength, leading to endanger the safety of structures [13]. Experiments on concretes have shown that the strength of concrete decreases with the increase of freezing-thawing cycles $[14,15]$. Therefore, the methods of concrete resistance to freezing-thawing have been studied by scholars, and the results indicated that adding fly ash and mineral powder in concrete can resist the freezing-thawing environment [16-19].

With the continuous development of the researches on the frost resistance durability of concrete at material level, it has become a hot spot to study the working mechanism and damage model of concrete structures in the freezethaw environment.

On the basis of concrete damage mechanics theory, Liu [20] established a concrete durability damage constitutive model to analyze the cumulative development process of concrete durability fatigue damage with probability method, and put forward a three-parameter Weibull distribution model of concrete damage evolution. Combining the damage degree theory of concrete and the experimental data, Ning [21] established the regression equation of the relationship between concrete damage degree and the number of freeze-thaw cycles and carried out the regression analysis and fracture prediction of fracture toughness under freezethaw action by LS-SVM. Based on the isotropic continuous damage mechanics theory, Ji et al. [22] considered the elastic modulus and Poisson's ratio under the damage condition as variables and established the concrete freeze-thaw damage failure criterion and concrete freeze-thaw damage constitutive model based on Ottosen's theoretical model, which was realized by compiling with the finite element program. $\mathrm{Fu}$ [23] introduced the damage factor $(D=0.34)$ as the basis for the failure of prestressed concrete structures. Liu et al. [24] studied the influence of freeze-thaw cycles on the damage characteristics of fiber-reinforced concrete materials and analyzed the mesomechanism of the freeze-thaw damage of fiber-reinforced concrete. Besides, they established the freeze-thaw damage constitutive model of fiber-reinforced concrete. With the help of rapid freeze-thaw cycle tests, Cheng and Gao [25] studied the freeze-thaw damage characteristics of polypropylene fiber-reinforced concrete and analyzed the freeze-thaw damage mechanism of polypropylene fiber-reinforced concrete. Also, they established the strength damage model of polypropylene fiber-reinforced concrete under the action of freeze-thaw cycle.

To sum up, it can be found that there have been many achievements in the research on the damage mechanism of concrete under single-factor environmental conditions (such as freeze-thaw environment and corrosion environment) at home and abroad, and many damage models have been established. However, there are few studies on the damage mechanism of concrete under the influence of multiple environmental factors. This paper studies the change of mechanical properties of concrete under the combined action of freeze-thaw and corrosion environment and establishes the damage evolution and constitutive model of concrete under marine corrosive and freeze-thaw environment. Lastly, based on the concrete damage model, the change laws of the longitudinal displacement, lateral deformation, and failure state of the concrete pile under the marine corrosion and freeze-thaw environment with time are studied.

\section{Experiment}

2.1. Experiment Sample. The 42.5 grade ordinary Portland cement produced by Xuzhou Zhonglian Cement Plant is used in this test. The coarse aggregate is gravel with particle size of $5 \sim 20 \mathrm{~mm}$, and the fine aggregate is river sand. The content of admixture concrete sample is shown in Table 1. The concrete sample size to test the compression strength is $100 \mathrm{~mm} \times 100 \mathrm{~mm} \times 100 \mathrm{~mm}$, while the sample size to measure the elastic modulus is $100 \mathrm{~mm} \times 100 \mathrm{~mm} \times 300$ $\mathrm{mm}$. The samples detach the mold after $24 \mathrm{~h}$ pouring. After the sample being removed from the mold, the brush hair, oil, and slurry on the bottom of the sample are cleaned with a steel wire brush. After that, the sample is placed in a curing room with the temperature of $20^{\circ} \mathrm{C}$ and the relative humidity of $95 \%$ for 28 days.

2.2. Test Method. The KDS-60 rapid freeze-thaw test machine was used to carry out freeze-thaw cycles on the samples, with the number of freeze-thaw cycles being 0,30 , 60 , and 90 times, respectively. In one freezing-thawing cycle, the freezing time and temperature are set as 2 hours and $256 \mathrm{~K}$. The dynamic elastic modulus and compressive strength of the concrete were measured.

The samples after freeze-thaw cycles were put into the artificial climate environment simulation laboratory for corrosion degradation. The samples were taken out after $0 \mathrm{~d}$, $30 \mathrm{~d}, 110 \mathrm{~d}, 190 \mathrm{~d}$, and $270 \mathrm{~d}$, respectively, and the mechanical properties were tested.

The corrosion environment is set as follows: salt spray spraying corrosion with mass concentration of 5\%, intermittent operation of salt spray spraying (spray for $12 \mathrm{~h}$, no spray for $12 \mathrm{~h}$ ), and ultraviolet light corrosion is used during the interval of spray stop.

The dynamic elastic modulus of concrete was tested by TD-W18 dynamic elastic modulus tester in different test stages. And the compressive strength of the specimen was tested by a YAS-5000 microcomputer-controlled electrohydraulic servo pressure testing machine. The loading speed was based on the compressive strength grade of the specimen, which was $0.5-0.8 \mathrm{MPa}$ per second when the 


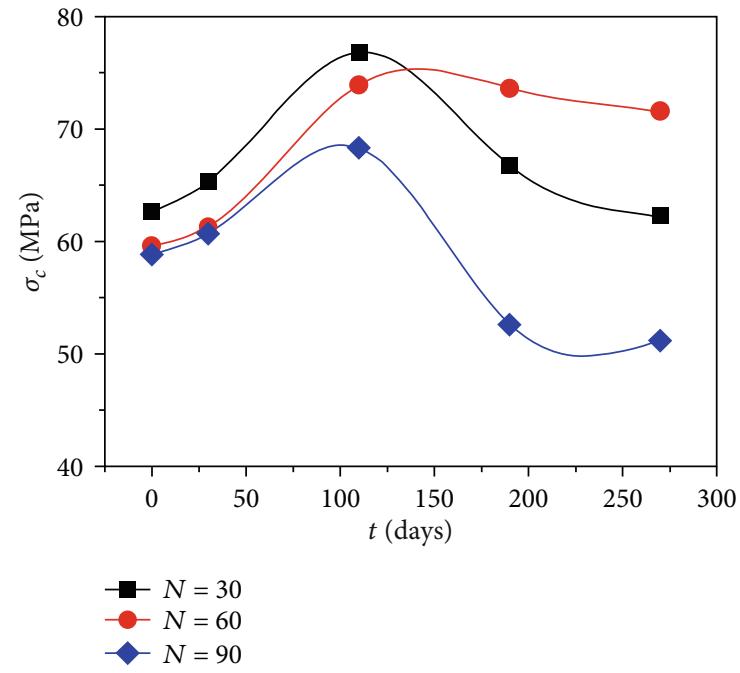

FIGURE 1: The variation curves of concrete compressive strength and corrosion time under different freeze-thaw cycles.

compressive strength of the specimen was greater than $30 \mathrm{MPa}$. Record the value of related physical quantity during loading. According to the concrete specimen under uniaxial compression test of axial load $(F)$-displacement $(l)$ curve, it is concluded that the admixture of concrete corrosion in different times after stress $(\sigma)$ and strain $(\varepsilon)$ process curve based on Equation (1) further analyzes concrete compressive strength and the concrete elastic modulus $E$ with the changing rule of the corrosion time.

$$
\begin{gathered}
\sigma=\frac{F}{A_{0}}, \\
\varepsilon=\frac{l}{l_{0}},
\end{gathered}
$$

where $A_{0}$ is the initial cross-sectional area of sample and $l_{0}$ is the initial height of sample.

\subsection{Test Results}

2.3.1. Compressive Strength of Concrete. It can be seen from Figure 1 that the compressive strength of concrete after corrosion for 30 days increases by about $4.21 \%$ when the freezethaw cycle $(N)$ is 30 times, compared with that of uncorroded concrete. When the corrosion time increases from $30 \mathrm{~d}$ to $110 \mathrm{~d}$, the compressive strength of concrete changes from $65.3 \mathrm{MPa}$ to $76.8 \mathrm{MPa}$, increasing by about $7.62 \%$. After that, the compressive strength of concrete decreases with an increase in corrosion time. The compressive strength of concrete changes from $76.8 \mathrm{MPa}$ to $66.7 \mathrm{MPa}$, decreasing by about $13.04 \%$, with the corrosion time changing from $110 \mathrm{~d}$ to $190 \mathrm{~d}$. When the corrosion time increases from $190 \mathrm{~d}$ to $270 \mathrm{~d}$, the compressive strength of concrete decreases by about $6.74 \%$, reducing from $66.8 \mathrm{MPa}$ to $62.3 \mathrm{MPa}$

When the freeze-thaw cycle is 60 times, the compressive strength of concrete after corrosion for 30 days increases by

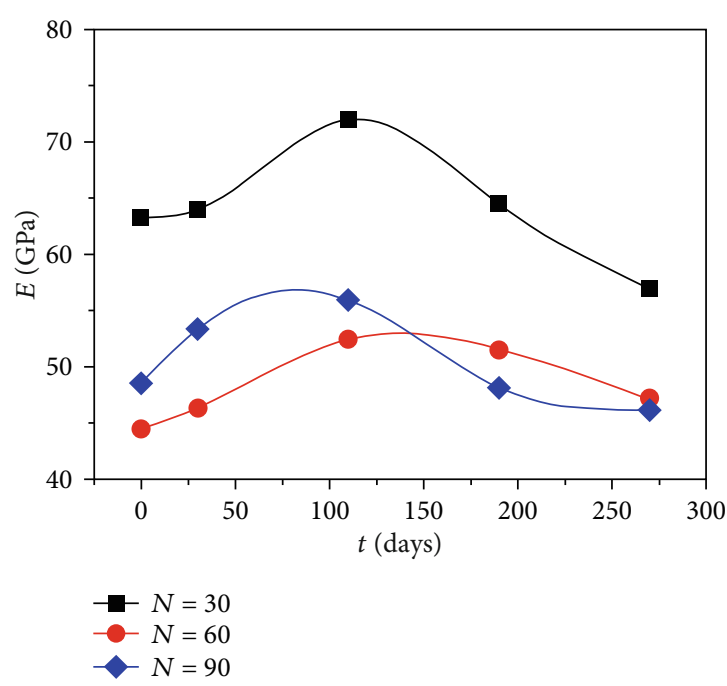

FIgURE 2: The variation curves of concrete elastic modulus and corrosion time under different freeze-thaw cycles.

about $2.61 \%$, compared with that of uncorroded concrete. When the corrosion time increases from $30 \mathrm{~d}$ to $110 \mathrm{~d}$, the compressive strength of concrete changes from $61.3 \mathrm{MPa}$ to $73.9 \mathrm{MPa}$, increasing by about $20.56 \%$. After that, the compressive strength of concrete begins to decrease with an increase in corrosion time. During the process of increasing the corrosion time from $110 \mathrm{~d}$ to $270 \mathrm{~d}$, the compressive strength of concrete decreases by $3.06 \%$, changing from $73.9 \mathrm{MPa}$ to $71.6 \mathrm{MPa}$.

In the case of the freeze-thaw cycle being 90 times, the compressive strength of concrete increases slightly $(\sim 3.06 \%)$ after corrosion for 30 days, compared with that of uncorroded concrete. When the corrosion time increases from $30 \mathrm{~d}$ to $110 \mathrm{~d}$, the compressive strength of concrete changes from $60.7 \mathrm{MPa}$ to $68.3 \mathrm{MPa}$, increasing by about $12.42 \%$. After that, the compressive strength of concrete begins to decrease with an increase in corrosion time, which is similar with the previous cases. During the corrosion time from $110 \mathrm{~d}$ to $190 \mathrm{~d}$, the compressive strength of concrete decreases by about $22.87 \%$, changing from $68.3 \mathrm{MPa}$ to $52.6 \mathrm{MPa}$. And the compressive strength of concrete decreases from $52.6 \mathrm{MPa}$ to $51.2 \mathrm{MPa}$ (reducing by about $2.66 \%$ ), with the corrosion time increasing from $190 \mathrm{~d}$ to $270 \mathrm{~d}$.

2.3.2. Elastic Modulus of Concrete. Figure 2 shows the variation curves of concrete elastic modulus and corrosion time under different freeze-thaw cycles. After 30 times of freezethaw corrosion, the elastic modulus of concrete corroded for $30 \mathrm{~d}$ increases slightly by $1.17 \%$, changing from 63.3 $\mathrm{GPa}$ to $64.0 \mathrm{GPa}$, compared with that of uncorroded concrete. When the corrosion time increases from $30 \mathrm{~d}$ to $110 \mathrm{~d}$, the elastic modulus of concrete changes from 64.0 GPa to $72.1 \mathrm{GPa}$, increasing by $12.51 \%$. However, the elastic modulus of concrete decreases from $72.1 \mathrm{GPa}$ to $64.5 \mathrm{GPa}$ in the process of increasing the corrosion time from $110 \mathrm{~d}$ to $190 \mathrm{~d}$, which decreases by about $10.47 \%$. The elastic modulus continues to decrease by $11.7 \%$, reducing 
TABLE 2: Values of the parameter $A_{1}$ of different freeze-thaw cycles and corrosion time.

\begin{tabular}{lcccc}
\hline \multirow{2}{*}{$t / \mathrm{d}$} & 0 & 30 & 60 & 90 \\
\hline 30 & $-9.69 E-3$ & $-7.15 E-5$ & $-9.02 E-4$ & $-3.45 E-12$ \\
110 & $-3.09 E-3$ & $-1.85 E-3$ & $-1.38 E-3$ & $-6.85 E-4$ \\
190 & $-6.23 E-4$ & $-1.69 E-5$ & $-5.60 E-4$ & $-3.88 E-3$ \\
270 & $-9.42 E-4$ & $-3.94 E-4$ & $-5.73 E-4$ & $-4.55 E-4$ \\
\hline
\end{tabular}

TABLe 3: Values of the parameter $A_{2}$ of different freeze-thaw cycles and corrosion time.

\begin{tabular}{lcccc}
\hline$t / \mathrm{d}$ & 0 & 30 & 60 & 90 \\
\hline 30 & 0.9637 & 0.9440 & 0.9731 & 0.9992 \\
110 & 0.9310 & 0.9077 & 0.9187 & 0.9571 \\
190 & 0.9390 & 0.9180 & 0.9200 & 0.9460 \\
270 & 0.9658 & 0.9285 & 0.8450 & 0.9253 \\
\hline
\end{tabular}

TABLE 4: Values of the parameter $\varepsilon_{0}$ of different freeze-thaw cycles and corrosion time.

\begin{tabular}{lcccc}
\hline$t / \mathrm{d}$ & 0 & 30 & 60 & 90 \\
\hline 30 & 0.01978 & 0.05032 & 0.04701 & 0.03788 \\
110 & 0.03469 & 0.03081 & 0.02663 & 0.02963 \\
190 & 0.02934 & 0.03880 & 0.03169 & 0.03782 \\
270 & 0.04024 & 0.03156 & 0.03644 & 0.04692 \\
\hline
\end{tabular}

from $64.5 \mathrm{GPa}$ to $57.0 \mathrm{GPa}$, with an increase in the corrosion time from $190 \mathrm{~d}$ to $270 \mathrm{~d}$.

In the case of 60 times of freeze-thaw corrosion, the elastic modulus of concrete increases slightly by $4.23 \%$ after $30 \mathrm{~d}$ corrosion, compared with that of uncorroded concrete. When the corrosion time increases from $30 \mathrm{~d}$ to $110 \mathrm{~d}$, the elastic modulus of concrete changes from $46.4 \mathrm{GPa}$ to $52.5 \mathrm{GPa}$, which increases by $13.19 \%$. After that, the elastic modulus of concrete begins to decrease with an increase in corrosion time. During the corrosion time from $110 \mathrm{~d}$ to $190 \mathrm{~d}$, the elastic modulus of concrete decreases by $1.65 \%$, changing from $52.5 \mathrm{GPa}$ to $51.6 \mathrm{GPa}$. While the elastic modulus of concrete decreases from $51.6 \mathrm{GPa}$ to $47.2 \mathrm{GPa}$, which decreases by about $8.60 \%$, with an increasing corrosion time from $190 \mathrm{~d}$ to $270 \mathrm{~d}$.

For freeze-thaw for 90 times, the elastic modulus of concrete after corrosion for $30 \mathrm{~d}$ has little change compared with that of uncorroded concrete. When the corrosion time increases from $30 \mathrm{~d}$ to $110 \mathrm{~d}$, the elastic modulus of concrete increases from $49.4 \mathrm{GPa}$ to $60.0 \mathrm{GPa}$, which increases by $9.41 \%$. However, the elastic modulus of concrete decreases by $12.76 \%$, changing from $54.0 \mathrm{GPa}$ to $47.1 \mathrm{GPa}$ in the process of increasing the corrosion time from $110 \mathrm{~d}$ to $190 \mathrm{~d}$. When the corrosion time increased from $190 \mathrm{~d}$ to $270 \mathrm{~d}$, the elastic modulus of concrete decreases from $47.1 \mathrm{GPa}$ to $46.2 \mathrm{GPa}$, decreasing by about $1.21 \%$.
TABLE 5: Values of the parameter $d x$ of different freeze-thaw cycles and corrosion time.

\begin{tabular}{lcccc}
\hline \multirow{2}{*}{$t / \mathrm{d}$} & 0 & 30 & 60 & 90 \\
\hline 30 & $2.74 E-3$ & $5.81 E-4$ & $1.89 E-3$ & $1.23 E-6$ \\
110 & $2.65 E-3$ & $1.82 E-3$ & $1.36 E-3$ & $1.26 E-3$ \\
190 & $1.37 E-3$ & $1.94 E-4$ & $1.25 E-3$ & $3.21 E-3$ \\
270 & $2.31 E-3$ & $8.60 E-4$ & $1.46 E-3$ & $1.45 E-3$ \\
\hline
\end{tabular}

Table 6: Fitting coefficients $a, b, c, d, e, f, g$, and $h$.

\begin{tabular}{lcccc}
\hline \multirow{2}{*}{ Coefficient } & \multicolumn{4}{c}{ Parameter } \\
& $A_{1}$ & $A_{2}$ & $\varepsilon_{0}$ & $d x$ \\
\hline$a$ & -0.0115 & 0.9981 & 0.0274 & 0.0028 \\
$b$ & 0.000413 & 0.000618 & 0.001493 & -0.000119 \\
$c$ & $9.29 E-05$ & -0.001636 & -0.000159 & $1.74 E-06$ \\
$d$ & $-4.68 E-06$ & $-2.35 E-05$ & $-2.18 E-05$ & $2.30 E-06$ \\
$e$ & $-2.34 E-06$ & $-3.80 E-06$ & $-8.37 E-06$ & $3.47 E-07$ \\
$f$ & $-1.98 E-07$ & $1.10 E-05$ & $1.78 E-06$ & $-1.03 E-07$ \\
$g$ & $1.94 E-08$ & $2.36 E-07$ & $8.85 E-08$ & $-1.65 E-08$ \\
$h$ & $7.46 E-09$ & $7.02 E-08$ & $5.77 E-08$ & $2.06 E-09$ \\
$k$ & $4.19 E-09$ & $-2.35 E-08$ & $1.00 E-08$ & $-1.41 E-09$ \\
$p$ & 0.0000 & $-1.97 E-08$ & $-3.87 E-09$ & $3.31 E-10$ \\
$R$-square & 0.8500 & 0.8629 & 0.7617 & 0.6642 \\
\hline
\end{tabular}

It can be seen from the above analysis that both freeze-thaw and corrosive environments have an effect on the strength of concrete materials. The content of chloride ions in the marine environment is much higher than other substances, and the damage caused by chloride ions to the reinforced concrete is obvious. The chloride ions invading into the concrete accelerate the corrosion of the reinforced. At present, the explanations for the damage mechanism caused by chloride ions to concrete can be concluded as follows: when chloride ions participate in chemical reactions, calcium hydroxide will be dissolved, so that calcium is resolved from the cement slurry. Therefore, in the early stage of corrosion, the micropores in concrete will be filled by hydration and corrosion products, and its microstructure is improved, and the strength of concrete is enhanced. As the corrosion progresses, the corrosion products continue to accumulate and expand, while the calcium hydroxide continues to separate out, resulting in damage to the microstructure of the concrete and a decrease in strength.

Freezing-thawing damage to concrete is fatal. Free water in concrete pore forms fatigue stress under the combined action of expansion pressure and osmotic pressure under the alternating positive and negative temperature, resulting in the destruction of concrete from the surface to the inside, which reduces the mechanical properties of concrete. It can be seen from the test results that the strength of the mixed concrete after freeze-thawing for 60 and 90 times without 
TABLE 7: Fitting coefficients $a, b, c, d, e, f, h, k$, and $p$.

\begin{tabular}{|c|c|c|c|c|c|c|c|c|c|c|}
\hline Parameter & $a$ & $b$ & $c$ & $d$ & $e$ & $f$ & $h$ & $k$ & $p$ & $R$-square \\
\hline Coefficients & 59.4 & -0.258 & 0.333 & $4.56 E-4$ & $1.82 E-6$ & -0.003 & $-4.73 E-6$ & $2.47 E-6$ & $4.41 E-6$ & 0.85 \\
\hline
\end{tabular}
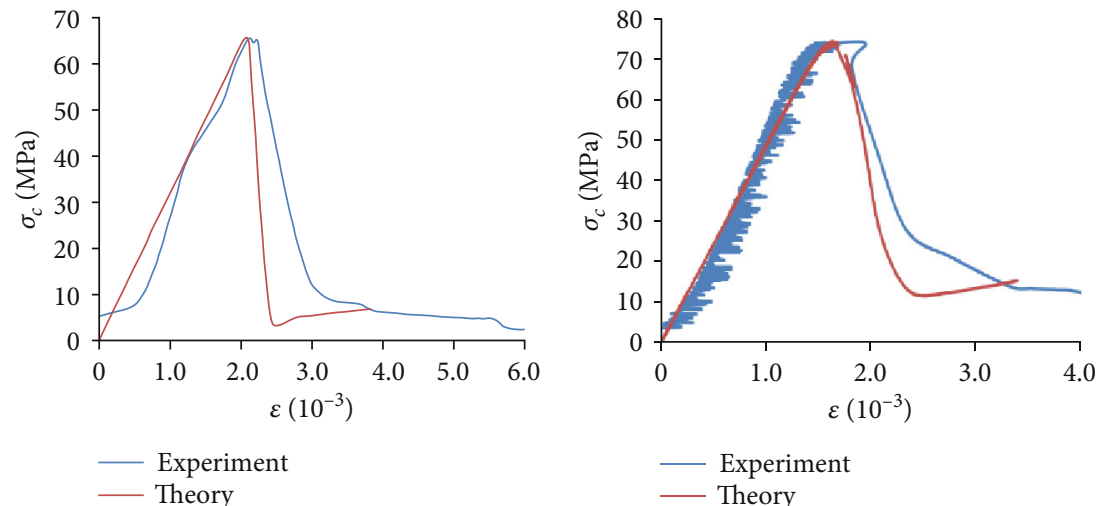

(a)

(b)

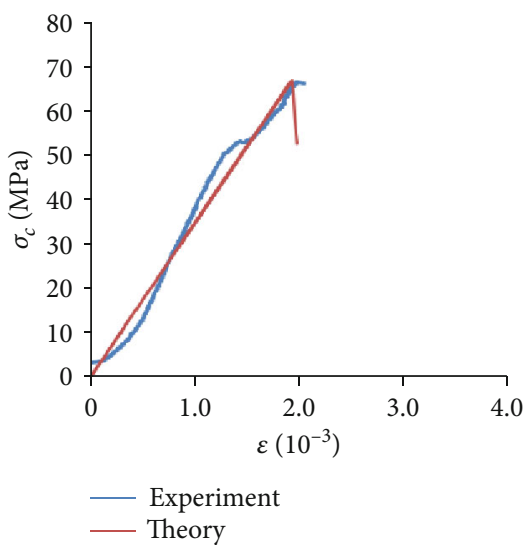

(c)

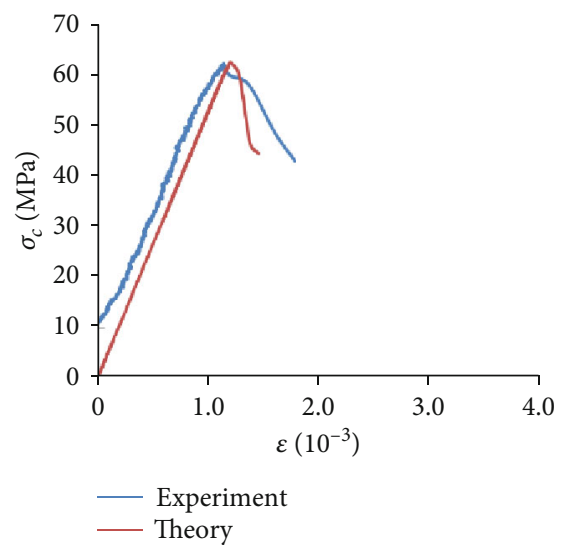

(d)

FIGURE 3: Experimental and theoretical curves of stress-strain of concrete with composite admixture under 30 (a), 110 (b), 190 (c), and 270 (d) days of corrosion after 30 freeze-thaw cycles.

corrosion is significantly lower than that of the concrete without freeze-thawing, indicating that the concrete is damaged. However, the change of concrete strength with corrosion time after 60 times of freezing and thawing is obviously different from that after 90 times of freezing and thawing, because the positive effect of corrosion is greater than the negative effect of freezing and thawing for 60 times. However, the positive effect of corrosion is less than the negative effect of freeze-thaw for concrete with 90 times of freeze-thaw, while the positive effect of corrosion is less than the negative effect of freeze-thaw for concrete with 90 times of freeze-thaw.

\section{Damage Evolution of Concrete Mixed with Admixtures}

3.1. Damage Evolution Model of Concrete under Uniaxial Compression. The change of secant elastic modulus is used to define the damage variables of concrete after corrosion and freeze-thaw cycle:

$$
D_{\mathrm{s}}=1-\frac{E_{\mathrm{F}}}{E_{\mathrm{F} 0}}
$$

where $E_{\mathrm{F} 0}$ is the secant elastic modulus of the linear elastic stage that is a lossless material and $E_{\mathrm{F}}$ is the instantaneous secant elastic modulus of concrete at the time of damage.

According to the test data of concrete under uniaxial compression, secant modulus and instantaneous secant modulus in linear elastic stage under uniaxial compression environment with different freeze-thaw cycles and corrosion time can be obtained. The instantaneous damage variable value $D_{\text {s }}$ can be calculated from Equation (2). The discrete values of the damage variable are fitted to obtain the expression of the change of the damage variable with the strain under uniaxial compression after different freeze-thaw cycles and corrosion time; namely, the damage evolution model of concrete under uniaxial compression is 


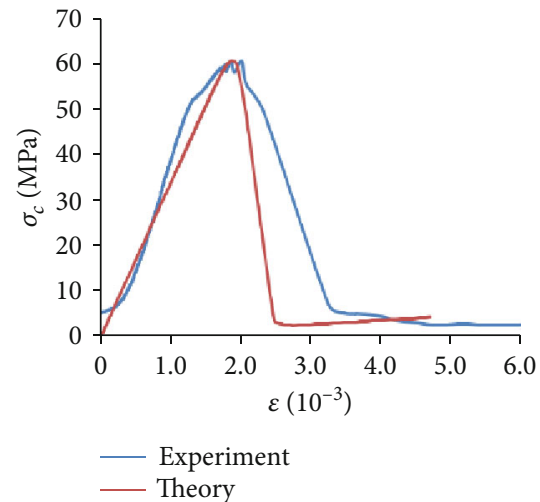

(a)

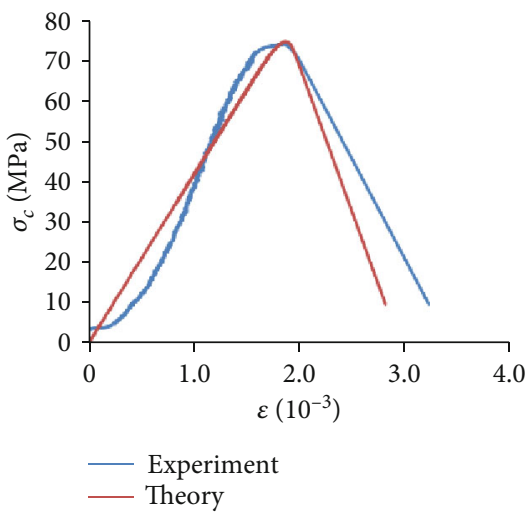

(c)

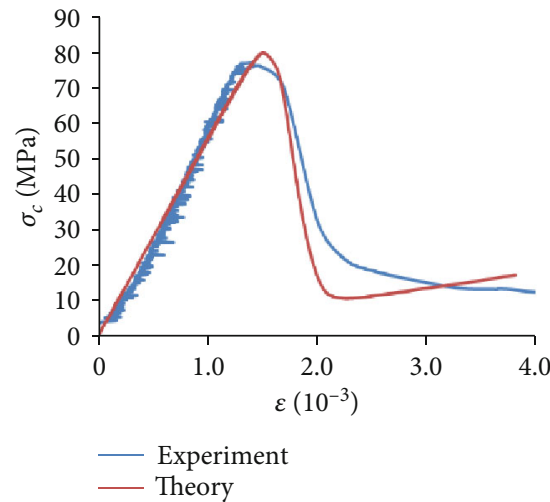

(b)

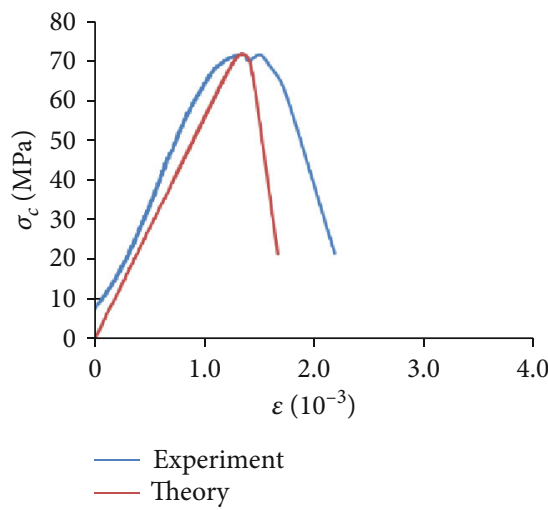

(d)

FIGURE 4: Experimental and theoretical curves of stress-strain of concrete with composite admixture under 30 (a), 110 (b), 190 (c), and 270 (d) days of corrosion after 60 freeze-thaw cycles.

obtained as follows:

$$
D_{s}(\varepsilon)=\frac{A_{2}+\left(A_{1}-A_{2}\right)}{1+\exp \left(\left(\varepsilon-\varepsilon_{0}\right) / d x\right)},
$$

where for different freeze-thaw cycles and corrosion time, the values of parameters $A_{1}, A_{2}, \varepsilon_{0}$, and $d x$ are shown in Tables 2-5.

By establishing the function relationship between the parameters, $A_{1}, A_{2}, \varepsilon_{0}$, and $d x$, and the number of freezethaw cycles and corrosion time, the damage evolution model of concrete under uniaxial compression considering the number of freeze-thaw cycles and corrosion time can be established. Assuming the following:

$$
\begin{aligned}
A_{1} & =A_{1}(N, t), \\
A_{2} & =A_{2}(N, t), \\
\varepsilon_{0} & =\varepsilon_{0}(N, t), \\
d x & =d x(N, t) .
\end{aligned}
$$

By subbing Equation (4) into the damage evolution model, the uniaxial compression damage evolution model of concrete considering the number of freeze-thaw cycles and cor- rosion time is as follows:

$$
D_{\mathrm{s}}(\varepsilon, N, t)=A_{2}(N, t)+\frac{A_{1}(N, t)-A_{2}(N, t)}{1+\exp \left[\varepsilon-\varepsilon_{0}(N, t) / d x(N, t)\right]},
$$

where the function of each parameter and freeze-thaw cycles $n$ and corrosion time $t$ could be established by fitting the discrete measured values of each parameter, shown in Equation (6) to Equation (9).

$$
A_{1}=a+b N+c t+d N^{2}+e N t+\mathrm{ft}^{2}+g N^{3}+h N^{2} t+k N t^{2}+p t^{3},
$$

$$
\begin{aligned}
& A_{2}=a+b N+c t+d N^{2}+e N t+\mathrm{ft}^{2}+g N^{3}+h N^{2} t+k N t^{2}+p t^{3}, \\
& \varepsilon_{0}=a+b N+c t+d N^{2}+e N t+\mathrm{ft}^{2}+g N^{3}+h N^{2} t+k N t^{2}+p t^{3}, \\
& d x=a+b N+c t+d N^{2}+e N t+\mathrm{ft}^{2}+g N^{3}+h N^{2} t+k N t^{2}+p t^{3},
\end{aligned}
$$

where the fitting coefficients of parameters $A_{1}, A_{2}, \varepsilon_{0}$, and $d x$ are shown in Table 6. 


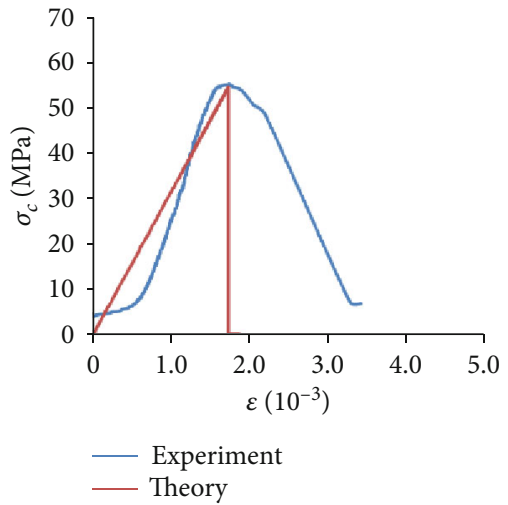

(a)

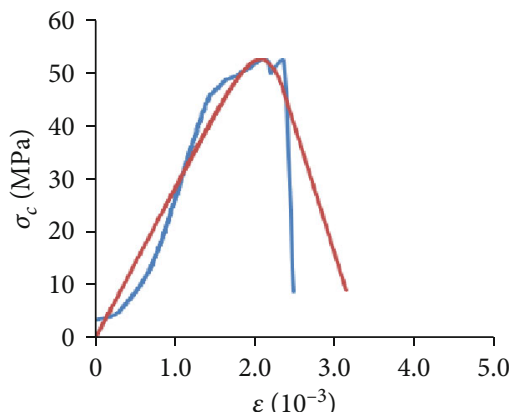

— Experimen

— Theory

(c)

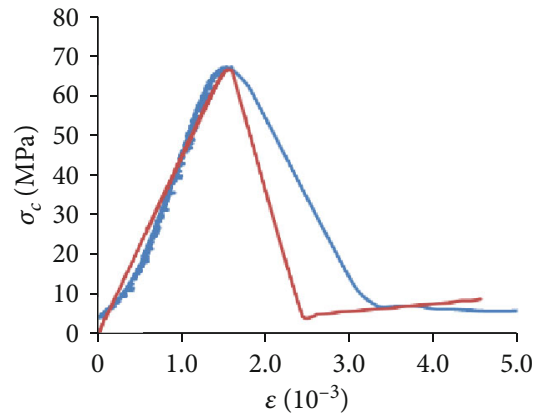

- Experiment Theory

(b)

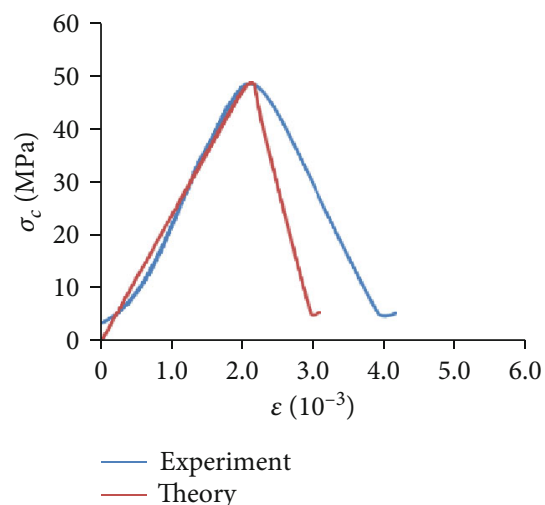

(d)

Figure 5: Experimental and theoretical curves of stress-strain of concrete with composite admixture under 30 (a), 110 (b), 190 (c), and 270 (d) days of corrosion after 90 freeze-thaw cycles.

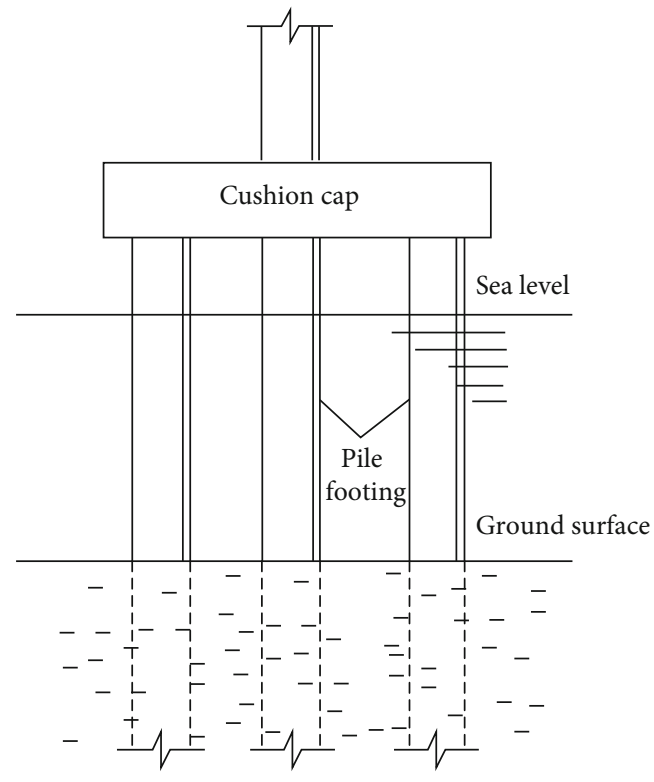

Figure 6: Structure diagram of a high-rise pile cap.
3.2. Damage Constitutive Model of Concrete under Uniaxial Compression. According to the assumption of equivalent strain,

$$
[\boldsymbol{\varepsilon}]=\frac{\left[\boldsymbol{\sigma}^{*}\right]}{[\mathbf{E}]}=\frac{[\boldsymbol{\sigma}]}{[\mathbf{E}]\left(1-\left[\mathbf{D}_{s}\right]\right)}
$$

That is,

$$
[\boldsymbol{\sigma}]=[\mathbf{E}][\boldsymbol{\varepsilon}]\left(1-\left[\mathbf{D}_{\mathrm{s}}\right]\right) .
$$

Here, $[\boldsymbol{\sigma}],\left[\boldsymbol{\sigma}^{*}\right],[\boldsymbol{\varepsilon}],[\mathbf{E}]$, and $\left[\mathbf{D}_{s}\right]$ are the nominal stress tensor, effective stress tensor, strain tensor, elastic modulus matrix, and damage matrix, respectively.

In the case of uniaxial compression,

$$
\sigma=E \varepsilon\left(1-D_{\mathrm{s}}\right)
$$

After substituting Equation (5) into Equation (12), it can obtain the following:

$$
\sigma=E \varepsilon\left\{1-A_{2}(N, t)-\frac{A_{1}(N, t)-A_{2}(N, t)}{1+\exp \left[\varepsilon-\varepsilon_{0}(N, t) / d x(N, t)\right]}\right\} .
$$



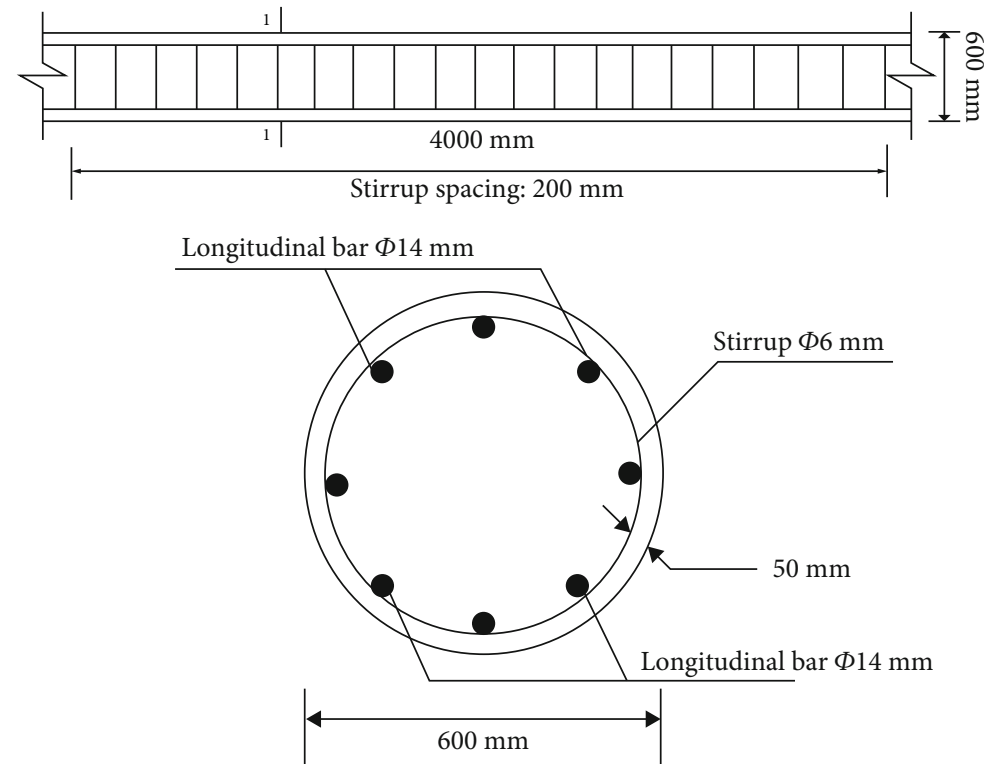

Figure 7: Circular pile size and reinforcement map of concrete (1-1 section).

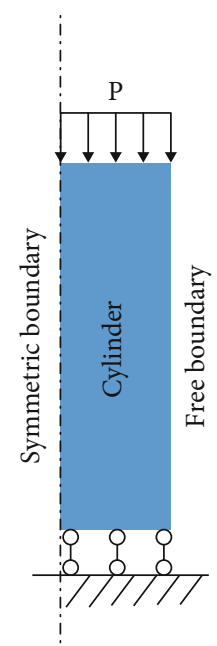

Figure 8: Boundary condition of circular pile.

When establishing the constitutive model of concrete under uniaxial compression considering the number of freeze-thaw cycles and corrosion time, it is necessary to consider the change of elastic modulus under different numbers of freeze-thaw cycles and corrosion time. Substituting the equation $E=E(N, t)$ into Equation (13) to obtain the concrete damage constitutive model considering the number of freeze-thaw cycles and corrosion time,

$$
\sigma=E(N, t) \varepsilon\left\{1-A_{2}(N, t)-\frac{A_{1}(N, t)-A_{2}(N, t)}{1+\exp \left[\varepsilon-\varepsilon_{0}(N, t) / d x(N, t)\right]}\right\},
$$

where the function of elastic modulus and freeze-thaw cycles $n$ and corrosion time $t$ could be established by fitting the discrete measured values of elastic modulus,

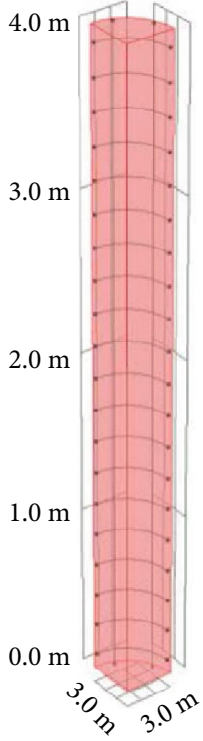

Figure 9: Geometric figure of numerical model.

TABle 8: Parameters for numerical simulation.

\begin{tabular}{lc}
\hline Parameters & Value \\
\hline Concrete density $\rho_{\mathrm{c}}\left(\mathrm{kg} / \mathrm{m}^{3}\right)$ & 2450 \\
The initial elastic modulus of concrete $E_{\mathrm{c}}(\mathrm{GPa})$ & 40 \\
Poisson's ratio of concrete $u_{\mathrm{c}}$ & 0.25 \\
Reinforcement density $\rho_{\mathrm{s}}\left(\mathrm{kg} / \mathrm{m}^{3}\right)$ & 7850 \\
The elastic modulus of reinforcement $E_{\mathrm{s}}(\mathrm{GPa})$ & 206 \\
Poisson's ratio of reinforcement $u_{\mathrm{s}}$ & 0.30 \\
$m_{\mathrm{hb}}$ & 1 \\
$S_{\mathrm{hb}}$ & 25 \\
Initial strength of concrete $\sigma_{\mathrm{c}}(\mathrm{MPa})$ & 60
\end{tabular}



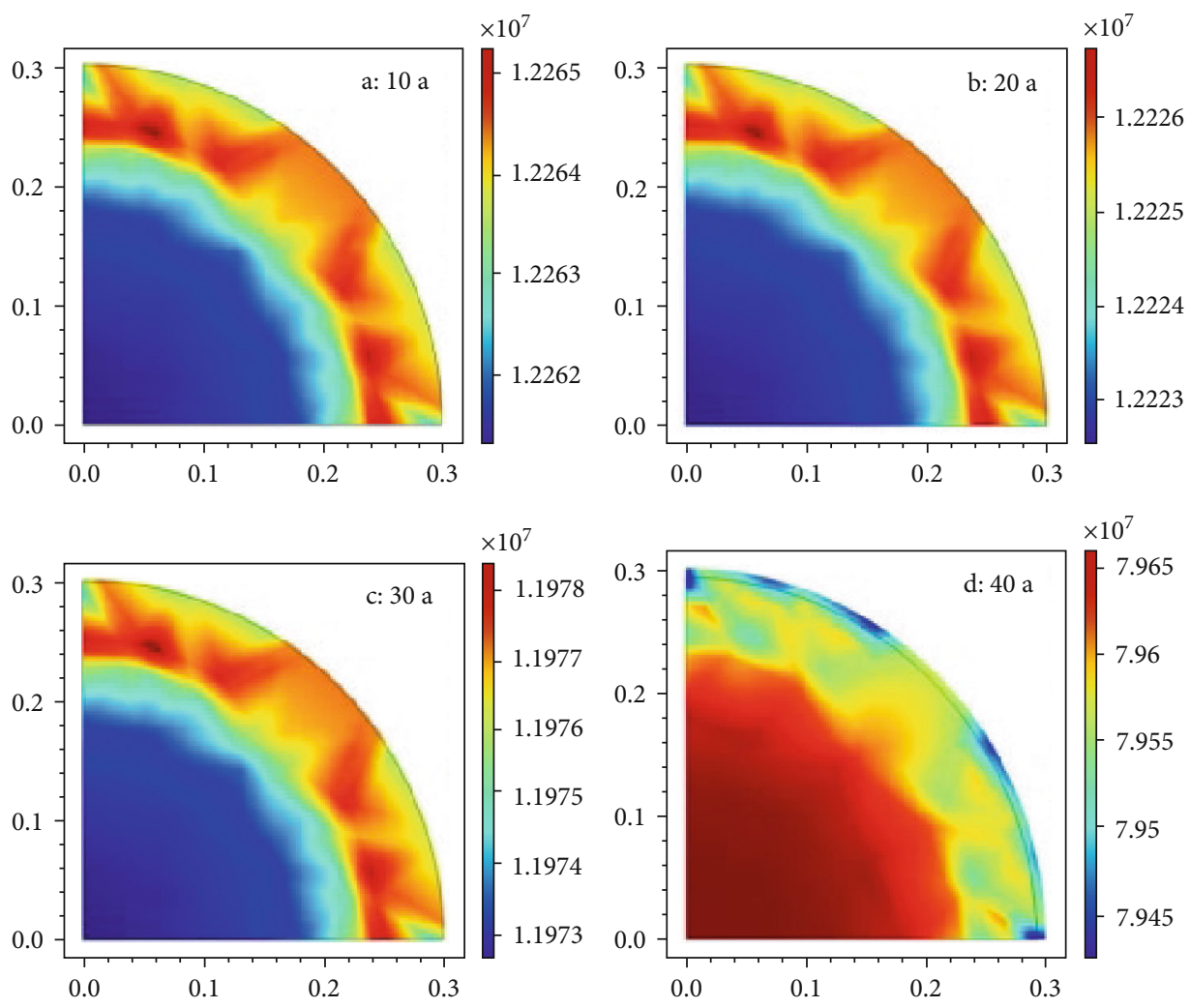

Figure 10: The von Mises stress distribution characteristics of middle section of circular pile under different times.

shown in Equation (15).

$$
E=a+b n+c t+d n^{2}+e n t+\mathrm{ft}^{2}+h n^{2} t+k n t^{2}+p t^{3} .
$$

Here, the fitting coefficients of elastic modulus are shown in Table 7.

Based on the above concrete damage constitutive model, the theoretical stress-strain curve of concrete under uniaxial compression can be obtained. Figures 3, 4, and 5 show the comparison between the experimental stress-strain curve and the theoretical curve of concrete under uniaxial compression after 30,60, and 90 cycles of freeze-thaw cycles and different corrosion times, respectively. It can be concluded that this constitutive model can well describe the stress-strain relationship of concrete under uniaxial compression under freeze-thaw and corrosion environments.

\section{Damage Evolution of Concrete Piles Mixed with Admixtures}

4.1. Project Background. High-rise pile cap is a common concrete pile structure, which is widely used in practical engineering. Figure 6 is a structure diagram of a high-rise pile cap at a wharf in Lianyungang area. It can be seen that one part of the pile foundation enters the ground, while part of that is immersed in sea water, and another part is exposed to the air.

Lianyungang port area is a warm temperate climate type. The average temperature of each month ranges from $1.5^{\circ} \mathrm{C}$ to $27.4^{\circ} \mathrm{C}$, with the highest in August and the lowest in Jan- uary. The average monthly maximum temperature is $29.9^{\circ} \mathrm{C}$, and the average minimum temperature is $-1.4^{\circ} \mathrm{C}$ [26]. So, the concrete structure of Lianyungang port area is not only affected by marine corrosion environment but also by freezing and thawing. Therefore, with the help of numerical calculation, this section analyzes the damage and failure process of the concrete pile member of the high-rise pile cap structure under the action of marine corrosion and freeze-thaw environment.

\subsection{Model Establishment}

4.2.1. Size of Circular Pile and Reinforcement of Concrete. Piles, which are located at sea level with above and below $2 \mathrm{~m}$ in Figure 6, are taken as the numerical model in this section, and the size and reinforcement diagram of concrete piles are shown in Figure 7.

Dimension unit in Figure 7 is in $\mathrm{mm}$. The pile diameter is $600 \mathrm{~mm}$, and the stirrup diameter is $6 \mathrm{~mm}$, with spacing being $200 \mathrm{~mm}$. The thickness of the protective layer is $50 \mathrm{~mm}$, and the longitudinal bar diameter is $14 \mathrm{~mm}$.

4.2.2. Numerical Model and Boundary Condition. Based on the COMSOL Multiphysics software, the numerical model of the circular pile is created, and the established damage evolution model and the damage constitutive model are also embedded in the software. The boundary condition of the circular pile is shown in Figure 8. The upper surface is subjected to static load $P$, and the bottom is given a sliding support, while the displacement in $Z$ direction is limited. Due to 


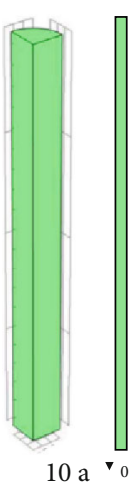

(a)

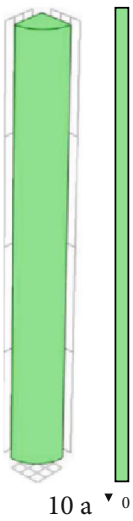

(e) (b)

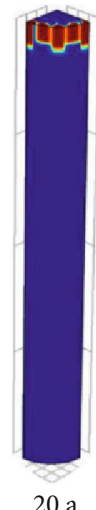

(f)

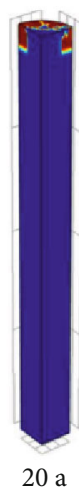

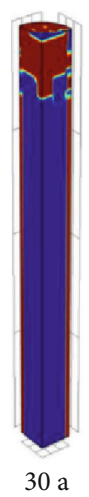

(c)

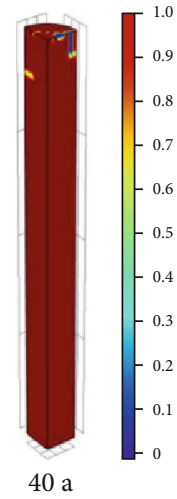

(d)

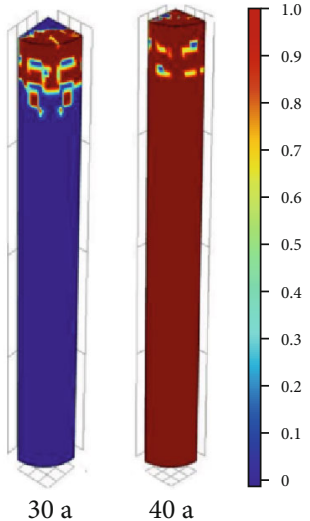

(h)
Figure 11: Failure state of concrete pile body at different times: (a) $10 \mathrm{a}$, (b) $20 \mathrm{a}$, (c) $30 \mathrm{a}$, (d) $40 \mathrm{a}$, (e) $10 \mathrm{a}$, (f) $20 \mathrm{a}$, (g) $30 \mathrm{a}$, and (h) $40 \mathrm{a}$.

the symmetry in this model, a quarter of the pile foundation is taken as the numerical calculation model in order to facilitate calculation, of which the numerical calculation geometry is shown in Figure 9.

\subsection{Material Characterization}

4.3.1. Accelerated Degradation Characteristics of Concrete Elastic Modulus under Freeze-Thaw and Corrosion. Here, the accelerated degradation model of concrete elastic modulus under the action of freeze-thaw and corrosion is defined as the product of the degradation model of concrete elastic modulus under freeze-thaw and the degradation model of concrete elastic modulus under corrosion, namely,

$$
\begin{aligned}
\frac{E}{E_{0}} & =\frac{E_{n}}{E_{0}} \times \frac{E_{t}}{E_{0}} \\
& =0.98 e^{-((4 \times n+0.7171) / 173.8)^{2}} \times\left(-0.000004 t^{2}+0.0005 t+1.0227\right),
\end{aligned}
$$

where $n$ is the number of freeze-thaw tests, $E_{n}$ is the elastic modulus of concrete after $n$ times freeze-thaw tests, $E_{0}$ is the initial elastic modulus of concrete, and $E_{t}$ is the elastic modulus of concrete after corrosion time $t$.
4.3.2. Accelerated Degradation Characteristics of Concrete Strength under Freeze-Thaw and Corrosion. Here, the accelerated degradation model of concrete strength under freezethaw and corrosion is defined as the product of the degradation model of concrete strength under freeze-thaw and the degradation model of concrete strength under corrosion, namely,

$$
\begin{aligned}
\frac{\sigma}{\sigma_{c 0}} & =\frac{\sigma_{c n}}{\sigma_{c 0}} \times \frac{\sigma_{c t}}{\sigma_{c 0}} \\
& =e^{-((4 \times n+10.88) / 167.4)^{2}} \times\left(-0.000004 t^{2}+0.0008 t+0.9987\right),
\end{aligned}
$$

where $n$ is the number of freeze-thaw tests, $\sigma_{c n}$ is the concrete strength after $n$ times freeze-thaw tests, $\sigma_{c 0}$ is the initial concrete strength, and $\sigma_{c t}$ is the concrete strength after corrosion time $t$.

4.3.3. Other Characterizations of Materials. The strength grade of concrete is C60, and the steel bar is Q235. Other main parameters and variables used in numerical simulation are shown in Table 8.

\subsection{Simulation Results}

4.4.1. Section Stress of Concrete Pile. Figure 10 shows the von Mises stress distribution and deformation diagram of the middle section in the round pile at 10,20,30, and $40 \mathrm{a}$. It can be seen from Figure 10 that the longitudinal displacement distribution of this section is not uniform. The stress value near the reinforcement is larger, which is mainly due to the stress concentration in reinforcement. In the early stage of corrosion, the place near the outer edge is the main bearing carrier. When the corrosion time is $40 \mathrm{a}$, the stress near the center is relatively large, while the stress at the outer edge is small, indicating that the concrete at the outer edge has nearly lost its bearing capacity, and the bearing body becomes the internal concrete.

4.4.2. Failure State of Concrete Pile. The internal and external damage and failure states of the circular pile at a time of 10, 20, 30 and $40 \mathrm{a}$ are shown in Figure 11, of which the red part represents the damaged area. It can be seen from Figure 11 that no damage occurs to the concrete pile when the time is $10 \mathrm{a}$. When time increases to $20 \mathrm{a}$, the failure area begins to appear near the outer edge of the main body on the top surface of the concrete, including the position of the longitudinal reinforcement. At $30 \mathrm{a}$, the failure area expands both laterally and vertically, and the bearing capacity of the pile decreases further. When time is $40 \mathrm{a}$, almost the whole area is damaged and the pile lost its bearing capacity. Once the failure of concrete pile occurs, the failure rate increases rapidly. The damage time of concrete pile is more serious at about $30 \mathrm{a}$.

\section{Conclusions}

(1) The uniaxial compression strength and elastic modulus of concrete under coupled freeze-thaw and 
corrosion environments are experimentally studied. The results show that both the compression strength and elastic modulus have the characteristics that first increase and then fall with the increase of the corrosion time

(2) Based on the macroscopic damage mechanics theory and the uniaxial compression test data of concrete, the damage constitutive model of concrete under marine corrosion and freeze-thaw environment is established. The theory results of the uniaxial compression stress-strain curves are well agreement with experiments

(3) Based on the COMSOL Multiphysics software and the established damage evolution model and the damage constitutive model, the stress distribution and the failure state of concrete pile are predicated. The results show that the failure areas begin to appear near the outer edge of the column on the top surface of the concrete when the time is $20 \mathrm{a}$, and the whole pile is damaged when the time is $40 \mathrm{a}$

\section{Data Availability}

The data used to support the findings of this study are included within the article.

\section{Conflicts of Interest}

The authors declare that they have no conflicts of interest.

\section{Acknowledgments}

Li Yan acknowledges the Key Research and Development Program of Xuzhou (No. KC18090). Zhang Lianying was supported by the National Natural Sciences Foundation of China (No. 51974296 and No. 52074240) and the Innovation Capacity Building Program of Xuzhou (No. KC18241). Ma Chao was supported by the Key Research and Development Program of Xuzhou (No. KC20176).

\section{References}

[1] P. Nath, P. K. Sarker, and W. K. Biswas, "Effect of fly ash on the service life, carbon footprint and embodied energy of high strength concrete in the marine environment," Energy and Buildings, vol. 158, pp. 1694-1702, 2018.

[2] Q. Wang, R. Pan, B. Jiang et al., "Study on failure mechanism of roadway with soft rock in deep coal mine and confined concrete support system," Engineering Failure Analysis, vol. 81, pp. 155-177, 2017.

[3] K. Ebrahimi, M. J. Daiezadeh, M. Zakertabrizi, F. Zahmatkesh, and A. Habibnejad Korayem, "A review of the impact of micro- and nanoparticles on freeze-thaw durability of hardened concrete: mechanism perspective," Construction and Building Materials, vol. 186, pp. 1105-1113, 2018.

[4] G. Ye, J. Hu, K. van Breugel, and P. Stroeven, "Characterization of the development of microstructure and porosity of cement-based materials by numerical simulation and ESEM image analysis," Materials and Structures, vol. 35, no. 10, pp. 603-613, 2002.

[5] D. Chen, P. H. Dong, and Y. D. Liao, "Retrospect and prospect of machanical study of corrosion in marine concrete," Corrosion and Protection, vol. 28, no. 12, pp. 630-632, 2007.

[6] S. Y. Cao, "Mechanical properties of corroded concrete," Journal of Southeast University, vol. 21, no. 4, pp. 89-91, 1991.

[7] Z. C. Chen and Y. W. Bao, "Influence of environmental corrosion on contact deformation and damage of concrete materials," Journal of Building Materials, vol. 4, no. 3, pp. 244245, 2001.

[8] M. Sahmaran, T. K. Erdem, and I. O. Yaman, "Sulfate resistance of plain and blended cements exposed to wettingdrying and heating-cooling environments," Construction and Building Materials, vol. 21, no. 8, pp. 1771-1778, 2007.

[9] J. Deja, "Freezing and de-icing salt resistance of blast furnace slag concretes," Cement \&Concrete Composites, vol. 25, no. 3, pp. 357-361, 2003.

[10] I. R. Almeida, "Resistance of high strength concrete to sulfate attack: soaking and drying test," in Concrete Durability, V. M. Malhotra, Ed., American Concrete Institute, Detroit, 1991.

[11] B. Pardhan, "Corrosion behavior of steel reinforcement in concrete exposed to composite chloride-sulfate environment," Construction and Building Materials, vol. 72, no. 15, pp. 103111, 2014.

[12] M. K. Mohammed, A. R. Dawson, and N. H. Thom, "Macro/micro-pore structure characteristics and the chloride penetration of self-coMPacting concrete incorporating different types of filler and mineral admixture," Construction and Building Materials., vol. 72, no. 15, pp. 83-93, 2014.

[13] D. T. Niu and Q. H. Xiao, "Analysis of cumulative damage characteristics and life prediction for the concrete in freezing-thawing circumstance," Journal of Xi'an University of Architecture and Technology, vol. 3, pp. 319-322+328, 2010.

[14] R. Polat, "The effect of antifreeze additives on fresh concrete subjected to freezing and thawing cycles," Cold Regions Science and Technology, vol. 127, pp. 10-17, 2016.

[15] D. Niu, L. Jiang, M. Bai, and Y. Miao, "Study of the performance of steel fiber reinforced concrete to water and salt freezing condition," Materials \& Design, vol. 44, pp. 267-273, 2013.

[16] T. Gonen, S. Yazicioglu, and B. Demirel, "The influence of freezing-thawing cycles on the capillary water absorption and porosity of concrete with mineral admixture," KSCE Journal of Civil Engineering, vol. 19, no. 3, pp. 667-671, 2015.

[17] H. Ma, H. Yu, and W. Sun, "Freezing-thawing durability and its improvement of high strength shrinkage compensation concrete with high volume mineral admixtures," Construction and Building Materials, vol. 39, pp. 124-128, 2013.

[18] X. J. Li, W. S. Wang, Z. Q. Zhu, and K. K. Zheng, "Investigation on durability behaviour and optimization of concrete with triple-admixtures subjected to freeze-thaw cycles in salt solution," Advances in Materials Science and Engineering, vol. 2021, Article ID 5572011, 16 pages, 2021.

[19] S. B. Luo, W. Liang, H. Wang, W. S. Wang, and R. J. Zou, "Durability evaluation of concrete with multiadmixtures under salt freeze-thaw cycles based on surface resistivity," Advances in Materials Science and Engineering, vol. 2021, Article ID 5567873, 18 pages, 2021.

[20] Y. Liu, Study on Stochastic Predicting Method for the Freeze Proof Durability of Concrete Based on Damage Theory, Zhejiang Univeristy, 2006. 
[21] Z. J. Ning, Research on Damage and Fracture of Concrete Subjected to Freeze-Thaw-Cycles, Harbin Institute of Technology, 2009.

[22] X. D. Ji, Y. P. Song, and J. Liu, "Study on frost damage constitutive model of concrete," Chinese Journal of Computational Mechanics, vol. 28, no. 3, pp. 461-467, 2011.

[23] F. Kai, Study on Fatigue Damage Mechanism of Pre-Stressed Concrete Structures under Freeze-Thaw Conditions, Jiangsu University, 2008.

[24] W. D. Liu, W. T. Su, and Y. M. Wang, "Research on damage model of fibre concrete under action of freeze-thaw cycle," Journal of Building Structures, vol. 29, no. 1, pp. 124-128, 2008.

[25] H. Q. Cheng and D. Y. Gao, "Experimental study on damage of polypropylene fiber concrete in freeze-thaw cycles," Journal of Southeast University (Natural Science Edition), vol. 40, no. 2, pp. 197-200, 2010.

[26] K. Sun, Z. Hu, H. Mao, and R. Zhang, "Period and jump analysis of temperature variation in Daqing in 40 recent years," Marine Forecasts, vol. 24, no. 3, pp. 108-111, 2007. 